\section{Therapie bei aktinischer Keratose? Der Arzt hat es in der Hand}

\author{
Die Art und Weise, wie Ärzte mit ihren Patienten kommunizieren, trägt viel \\ zur Therapieentscheidung bei. So willigen Patienten am ehesten in eine \\ Therapie bei aktinischer Keratose ein, wenn der Arzt diese als Krebsvorstufen \\ darstellt. Betont er hingegen, dass die Läsionen weitgehend harmlos sind, ist \\ der Anteil der Therapiebegeisterten deutlich geringer.
}

$\mathrm{H}^{2}$ autärzte aus den USA hatten 228

Patienten einer dermatologischen Klinik sowie 311 Teilnehmern einer Online-Umfrage fünf verschiedene Statements zur aktinischen Keratose vorgelegt. Bei jedem sollten die Teilnehmer entscheiden, ob sie einer Therapie zustimmen würden. Die Statements lauteten folgendermaßen:

- Aktinische Keratosen sind durch Sonnenstrahlung verursachte Hautflecken. Etwa 0,5\% der aktinischen Keratosen entwickeln sich in lebensbedrohlichen Hautkrebs, $25 \%$ verschwinden wieder von selbst.

-Aktinische Keratosen sind durch Sonnenstrahlung verursachte Hautflecken. Etwa 0,5\% der aktinischen Keratosen entwickeln sich in lebensbedrohlichen Hautkrebs, $75 \%$ verändern sich nicht.
_Aktinische Keratosen sind durch Sonnenstrahlung verursachte Hautflecken. Etwa 99,5\% der aktinischen Keratosen entwickeln keinen Hautkrebs und $25 \%$ verschwinden von selbst.

- Aktinische Keratosen sind durch Sonnenstrahlung verursachte Hautflecken. Etwa 99,5\% der aktinischen Keratosen entwickeln keinen Hautkrebs und $75 \%$ verändern sich nicht.

- Aktinische Keratosen sind Krebsvorstufen.

Wie zu erwarten, würden sich fast alle Teilnehmer (92\%) für eine Therapie entscheiden, wenn sie im fünften Statement nur erfahren, dass es sich bei den Läsionen um Krebsvorstufen handelt, aber nicht, dass eine ernsthafte Krebserkrankung daraus nur höchst selten entsteht. Am geringsten war die Zustimmung beim dritten Statement mit 58\%, wenn den
Teilnehmern erläutert wurde, dass die allermeisten aktinischen Keratosen keine gefährlichen Tumoren bilden und ein Viertel wieder von selbst verschwindet.

Fazit: Betonen Ärzte bei einer aktinischen Keratose die Präkanzerose, überzeugen sie fast alle Patienten von einer Behandlung. Erläutern sie hingegen, dass die Läsionen nur äußerst selten entarten, will nur die Hälfte eine Therapie. Für die Autoren erläutert das Beispiel, wie wichtig die Wortwahl der Ärzte und eine fundierte Diskussion über tatsächliche Risiken für die Therapieentscheidung sind. Letztlich beeinflusst der Arzt durch seine Kommunikation bewusst oder unbewusst die Therapieakzeptanz.

Darüber hinaus dürften die Ergebnisse der Umfrage für die dermatologische Praxis wenig relevant sein, da die allermeisten Teilnehmer nicht vor einer Therapieentscheidung standen. Zudem wurden allen Teilnehmern alle fünf Statements vorgelegt. Die ersten Statements haben jedoch mit hoher Wahrscheinlichkeit die Resultate für die folgenden beeinflusst.

Thomas Müller

Berry K et al. Influence of Information Framing on Patient Decisions to Treat Actinic Keratosis. JAMA Dermatol 2017; 153: 421-6

\title{
Balanitis circinata
}
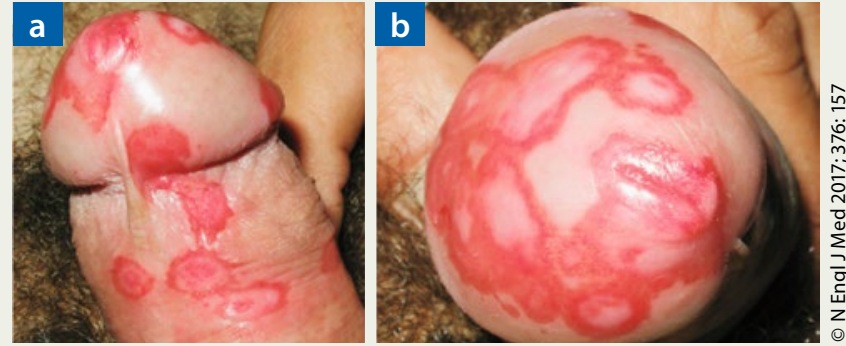

Scharf markierte, ringförmige Plaques an der Glans penis (a), Entzündung am Orificium externum (b)

Ein 37-jähriger Mann stellte sich mit Hautläsionen am Penis vor. Er gab an, dass er etwa $4 \mathrm{~kg}$ an Gewicht verloren hatte, sich müde und leistungsschwach fühlte und Rückenschmerzen hatte. Gastrointestinale Symptome lagen nicht vor. Zwei Monaten zuvor hatte er eine Episode von Dysurie und Ausfluss aus der Harnröhre gehabt, doch beides hatte sich spontan zurückgebildet.
Der Mann stand nicht unter einer Dauermedikation, die medizinische Vorgeschichte war unauffällig.

Bei der Untersuchung erkannte man gerötete, scharf markierte, ringförmige Plaques an der Glans penis und eine entzündliche Reaktion am Orificium externum (Abb. a, b). Zudem wiesen beide Augen eine konjunktivale Injektion auf. Der HIV-Test war positiv. Die Viruslast betrug 15.000 Kopien/ml, die CD4-Zellzahl 172/ $\mu$ l. Der Test auf Rheumafaktor fiel negativ aus, der HLA-B27-Test hingegen positiv. Serologische Untersuchungen auf Hepatitis $B$ und C sowie Syphilis waren negativ. Die PCR in einem Urethralabstrich ergab Chlamydia trachomatis.

Der Mann wurde mit einer Einzeldosis von $1 \mathrm{~g}$ Azithromycin behandelt, zusätzlich begann man eine antiretrovirale Therapie. Weil die Veränderungen am Penis vier Wochen später immer noch bestanden, behandelte man mit 0,1\%-Tacrolimus-Creme. Innerhalb von zehn Tagen kam es zur vollständigen Rückbildung.

Prof. Hermann S. FüeßI

Pulido-Perez A et al. Circinate balanitis. N Engl J Med 2017; 376: 157 